\title{
Effect of Tin Addition on the Corrosion Behavior of Lead-Calcium-Tin Grids in Lead-Acid Batteries
}

\author{
Lourdes Patricia L. Carreon, Michelle Angelica A. de Guzman*, Stan Kristian G. Ejera, Alyssa C. Ong \\ Department of Mining, Metallurgical and Materials Engineering, University of the Philippines-Diliman, Philippines
}

Copyright (C) 2015 by authors, all rights reserved. Authors agree that this article remain permanently open access under the terms of the Creative Commons Attribution License 4.0 International License

\begin{abstract}
Pb}-\mathrm{Ca}-\mathrm{Sn}$ alloys are used as grids in lead-acid batteries with $\mathrm{Ca}$ concentrations that range from 0.03-0.05 wt.\%. Grids that contain 0.03 wt.\% Ca have been proven to be resistant to corrosion, making them the ideal alloys for positive and negative grids of stationary batteries. Additives such as $\mathrm{Sn}$ have been added to improve the corrosion resistance, the electrochemical and the mechanical properties of the battery. This study aims to determine the effect of Sn coating on the corrosion behavior and the service life of $\mathrm{Pb}-\mathrm{Ca}-\mathrm{Sn}$ grids. The corrosion behavior was determined using weight loss method. Three batteries, each one composed of six corrosion cells, were prepared. Four positive plates, namely one control grid and three experimental grids, comprise each corrosion cell. The grids were submerged in sulfuric acid $\left(\mathrm{H}_{2} \mathrm{SO}_{4}\right)$ with a specific gravity of 1.28 and charged with $1.25 \mathrm{~A}$. Energy dispersive X-ray spectroscopy (EDX) was used to determine the composition of the grids and surface morphology was examined using scanning electron microscopy (SEM). Single factor analysis of variance (ANOVA) at $95 \%$ confidence level, suggests that the amount of Sn coating significantly affects the corrosion behavior of the grids. Results show that corrosion resistance of grids greatly improves with increasing thickness of Sn coating.
\end{abstract}

Keywords Corrosion, Corrosion Rate, Electrodeposition, $\mathrm{Pb}-\mathrm{Ca}-\mathrm{Sn}$ Alloy, Weight Loss Method

\section{Introduction}

The $\mathrm{Pb}-\mathrm{Ca}-\mathrm{Sn}, \mathrm{Pb}-\mathrm{Ca}$ and $\mathrm{Pb}-\mathrm{Sn}$ grids are the three types of grids that comprise the entire maintenance-free valve-regulated lead-acid (VRLA) batteries. The corrosion of these grids is one of the major problems in the battery industry because it shortens the battery life [1].

The rate of corrosion $(\mathrm{mm} / \mathrm{yr})$ can be approximated using

$$
\text { Corrosion Rate }=\frac{K W}{\rho A t}
$$

where $K$ is a factor equal to $8.76 \times 10^{4}$ (for $\mathrm{mm} /$ year or mmy units), $W$ the weight loss (g), $\rho$ the density of the material $\left(\mathrm{g} / \mathrm{cm}^{3}\right), A$ the area of the exposed specimen $\left(\mathrm{cm}^{2}\right)$ and $t$ the exposure time (hr) [2].

To improve corrosion resistance, an alloying element is usually added to the base metal. In lead-acid batteries, the addition of As, $\mathrm{Sn}$, and $\mathrm{Ag}$ reduces the corrosion rate. These substances provide a barrier which hinders contact between the electrolyte and the electrode. Electrochemical corrosion will not occur due to the lack of interaction between the anode and the cathode $[3,4]$.

Alloying $\mathrm{Sn}$ to $\mathrm{Pb}-\mathrm{Ca}$ improves the electrochemical and the mechanical properties of the grids, as well as the corrosion rate and the structure of the alloy. Sn has the ability to thin out the lead oxide $(\mathrm{PbO})$ layer and increase the conductivity of the semiconductor $\mathrm{PbO}$ layer $[5,6]$. In a study conducted by $\mathrm{Li}$ et al., it was found that $\mathrm{Sn}$ improves the conductivity of the passive film formed on lead-alloys and decreases the impedance of the anodic film through linear sweep voltage (LSV) and alternating current voltammetry (ACV) respectively [6]. It was observed that too much $\mathrm{Sn}$ content, however, can intensify the self-discharge of the lead-acid battery $[7,8]$.

Apart from adding alloying elements, direct coating can also be used to passivate a material from corrosion. Since the grids are exposed to corrosive industrial environment, tin coating with thickness within 2.54-15.24 microns is to be deposited [9]. The thickness of the electrodeposited Sn may be calculated using Faraday's Law

$$
\mathrm{h}=\frac{\mathrm{ZIt}}{\mathrm{ad}}
$$

where $h$ is the thickness $(\mathrm{cm}), Z$ the electrochemical equivalent ( $\left.\mathrm{g} \mathrm{C}^{-1}\right), I$ the current (A), $t$ the plating time (s), $a$ the plated surface area $\left(\mathrm{cm}^{2}\right)$ and $d$ the density of the deposit $\left(\mathrm{g} \mathrm{cm}^{-3}\right)$ [10]. Eqn. 2 shows a direct relationship between plating time and coating thickness, which was observed by Maltanava et al. and Gu et al. when they electrodeposited tin films on copper foil $[11,12]$.

This study focuses on the effect of Sn coating on the corrosion behavior of $\mathrm{Pb}-\mathrm{Ca}$-Sn grids. Possible effects of the grid production process on the corrosion behavior are 
beyond the scope of the study. Only one surface area was assumed for all grids when the corrosion rates were calculated because the former is difficult to measure due to the shape of the grids. The mechanical properties as well as the economic-related concerns of tin-coated grids were not investigated.

\section{Main Body}

The grids were coated with Sn through electrodeposition. Grids with three different coating thicknesses within the specified range were produced based on the following deposition times: one minute, two minutes and three minutes [9]. Considering Faraday's Law shown in Equation 2, it can be expected that the grid coated by three minutes would have the greatest amount of $\mathrm{Sn}$ since plating time is directly proportional to coating thickness [10].

Three batteries, each composed of six corrosion cells, were set up. Each corrosion cell contained one control grid and three experimental grids that were coated with tin at different durations. The grids were covered with separators and submerged in sulfuric acid $\left(\mathrm{H}_{2} \mathrm{SO}_{4}\right)$ with a specific gravity of 1.28 and charged with $1.25 \mathrm{~A}$. The first battery was exposed for two days while half of the second battery was exposed for four days, the other half for six days, half of the third battery for eight days, and the other half for ten days.

Weight loss was measured as a function of time. As shown in Figure 1, the uncoated control grid experienced the greatest material loss at all times. In comparison, grids that were coated for three minutes markedly exhibited lower material loss. These observations may be accounted to the $\mathrm{Sn}$ content of each grid, where the grid coated by three minutes having the highest amount of Sn.

The corrosion rate for each grid was also computed using Equation 1 and plotted as a function of time. As shown in Figure 2 the corrosion rate pattern was observed to increase and decrease in an inconsistent manner due to non-ideal conditions of the experiment. Nevertheless, it was seen that at all times, the control grid has the highest corrosion rate whereas the grid coated by three minutes the lowest.

A scanning electron microscope (SEM) was used to observe the surface morphology of the grids prior to, during and after corrosion. As seen in Figure 3a, there is a clear difference in surface texture between the control grid and the Sn-coated experimental grids.

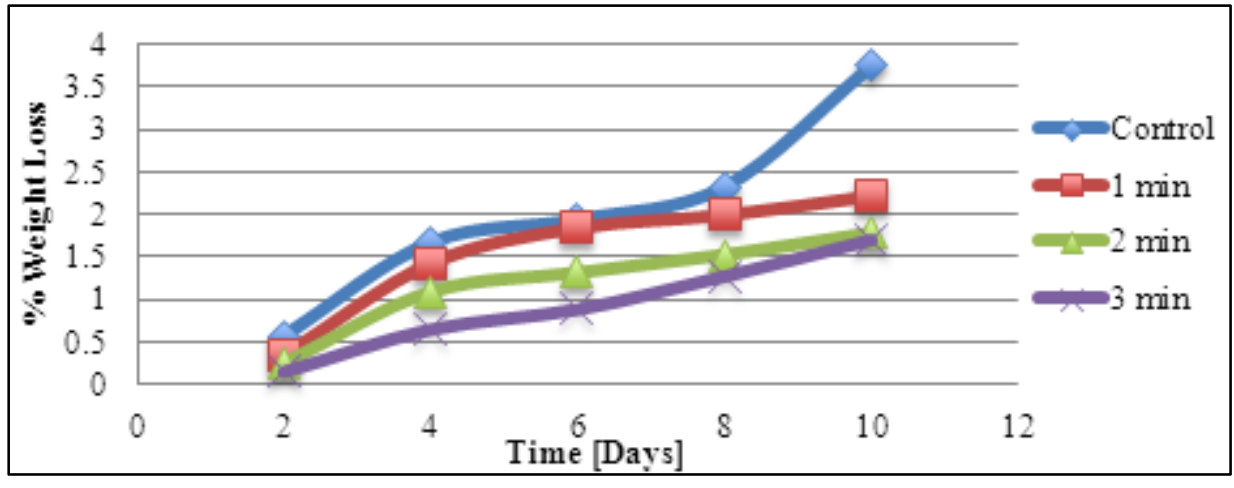

Figure 1. Plot of \% weight loss vs. time of the four setups.

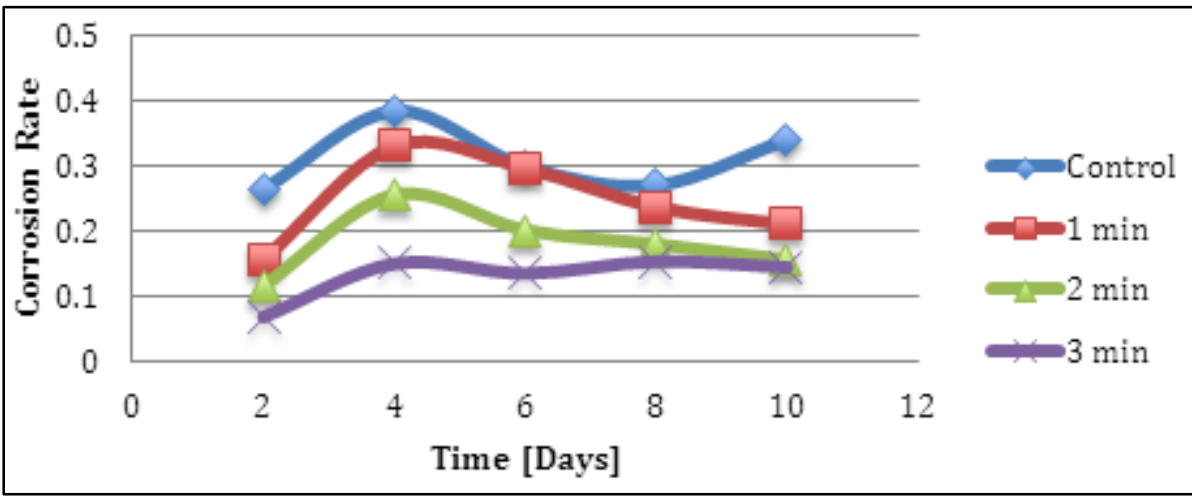

Figure 2. Plot of corrosion rate vs. time of the four setups. 


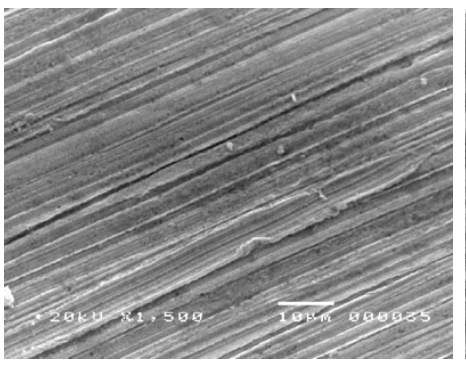

(a)

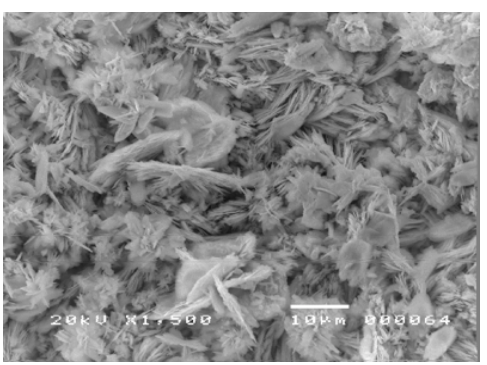

(b)

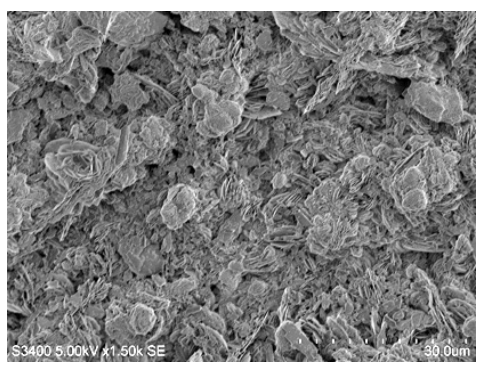

(c)

Figure 3. Surface structure of the control grid (a) prior to corrosion (b) after 6 days of exposure (c) after 10 days of exposure.

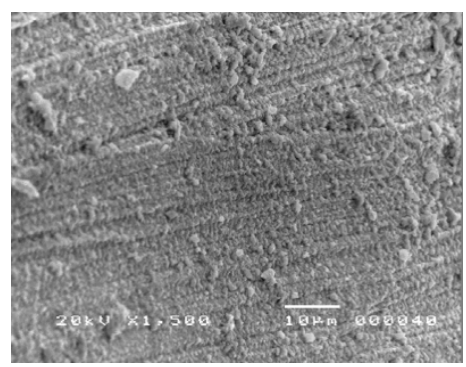

(a)

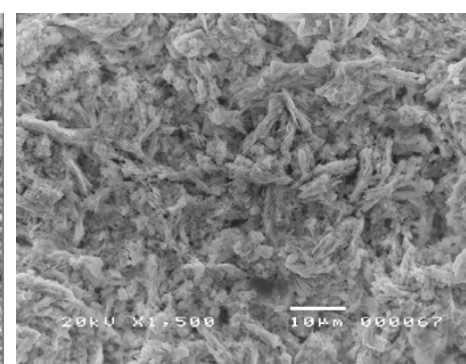

(b)

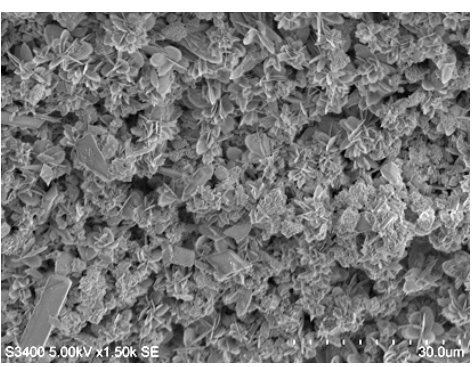

(c)

Figure 4. Surface structure of the grid coated by 1 minute (a) prior to corrosion (b) after 6 days of exposure (c) after 10 days of exposure.

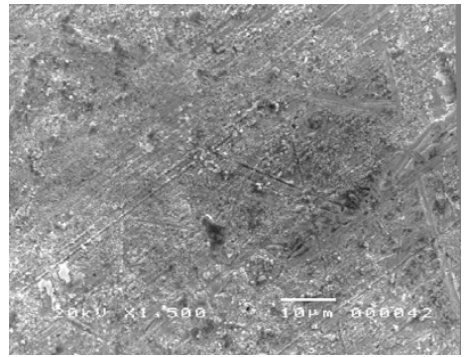

(a)

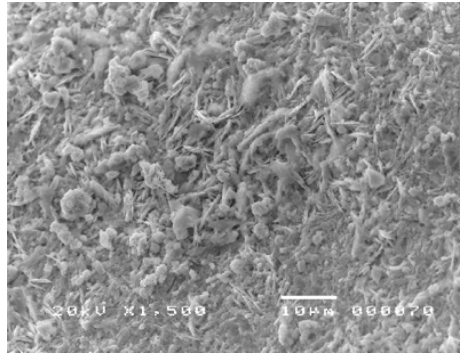

(b)

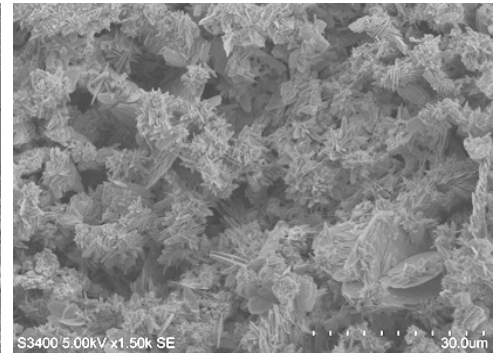

(c)

Figure 5. Surface structure of the grid coated by 2 minutes (a) prior to corrosion (b) after 6 days of exposure (c) after 10 days of exposure.

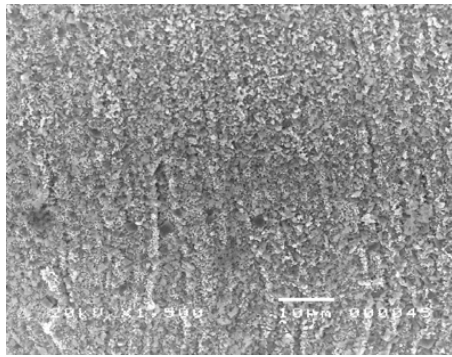

(a)

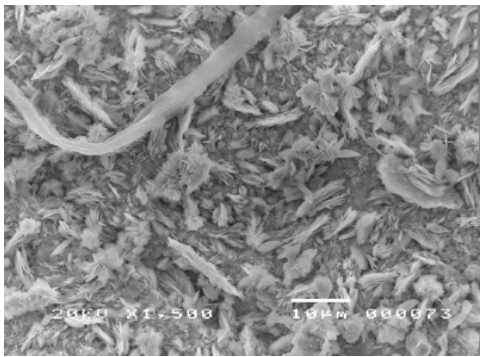

(b)

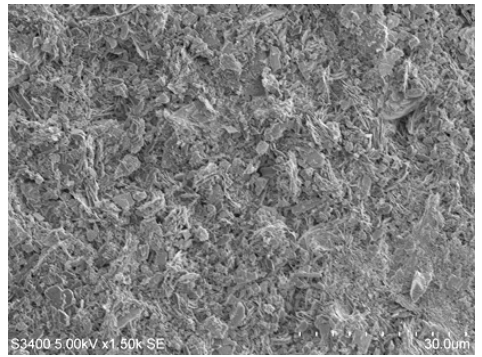

(c)

Figure 6. Surface structure of the grid coated by 3 minutes (a) prior to corrosion (b) after 6 days of exposure (c) after 10 days of exposure.

As seen in Figures 4a-6a, observable Sn coating particles formed on the surface of the grids. It was also observed that as deposition time increased, more particles formed on the surface. Moreover, it was observed that the size of clusters on the corrosion layer increased after ten days of corrosion. In summary, the control grid produced more oxide scales compared to the other grids, with the grids coated for three minutes having the observably least amount.

Energy dispersive $\mathrm{x}$-ray spectroscopy (EDX) was also used to identify the elements present on the surface of the grids prior to corrosion, after six days of exposure, and after ten days of exposure. Average values of each grid were then calculated and plotted.

As shown in Figure 7, the amount of Sn on the grids increased with longer deposition time. It was observed that the grid coated by three minutes has more Sn content prior to corrosion, after six days of exposure, and after ten days of exposure. This may be supported by the SEM images shown 
in Figure 6, in which more Sn particles and less oxide scales can be found on the surface of the grid.

Single factor analysis of variance (ANOVA) at 95\% confidence level was conducted to determine if the difference of the weight loss and corrosion behavior of the four grid setups is significant. From the generated equation in Figure 8, where -0.3734 is the slope, there is a decrease of $0.3734 \%$ on the weight loss of the grids for every 1 unit increase of $\mathrm{Sn}$ coating. Consequently, from the generated equation in Figure 9, where -0.0596 is the slope, there is also a decrease of 0.0596 on the corrosion rate of the grids for every 1 unit increase of $\mathrm{Sn}$ coating. From these relationships, it can then be deduced that $\mathrm{Sn}$ coating significantly affects the $\%$ weight loss and the corrosion rate of the grids; and that increasing the Sn coating content causes the corrosion rate to decrease and the corrosion resistance of the material to improve.

The conclusion that Sn content significantly affects the \% weight loss and the corrosion rate of the grids is supported by the study conducted by Takehara, Kanamura and Makoto which deduces the ability of $\mathrm{Sn}$ to thin the lead oxide $(\mathrm{PbO})$ layer [5]. Also, a study conducted by Le, Morrison and Vaccaro explains how the addition of $\mathrm{Sn}$ in lead $(\mathrm{Pb})$ alloys decreases the corrosion rate of the material. The corrosion resistance of the material and the over potential of oxygen evolution in $\mathrm{Pb}$ alloys are said to be directly proportional to Sn content [13]. Lastly, according to Li et al., the current of oxygen evolution decreases with increasing Sn content [6].

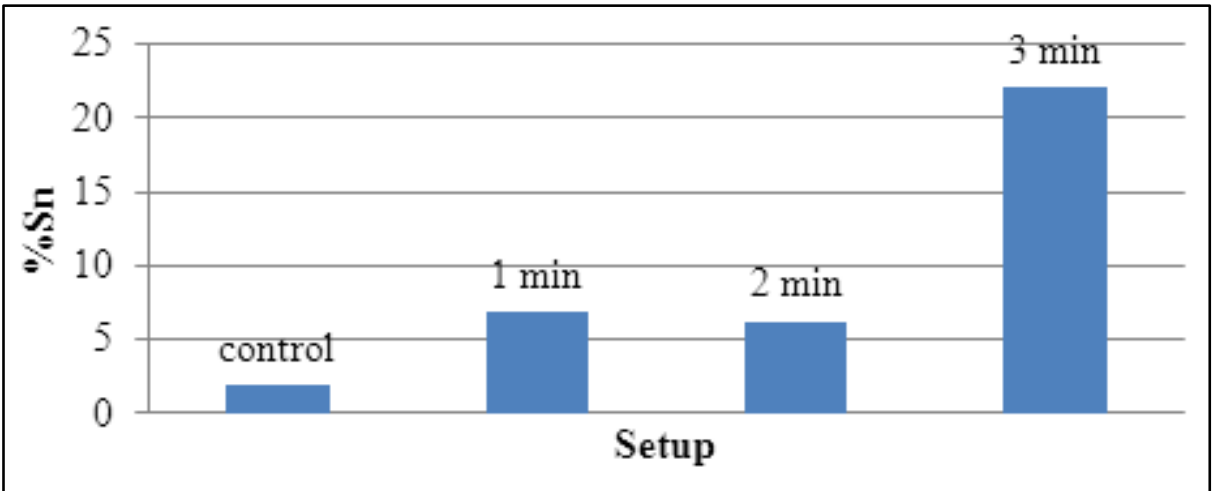

Figure 7. \% Sn present according to EDX.

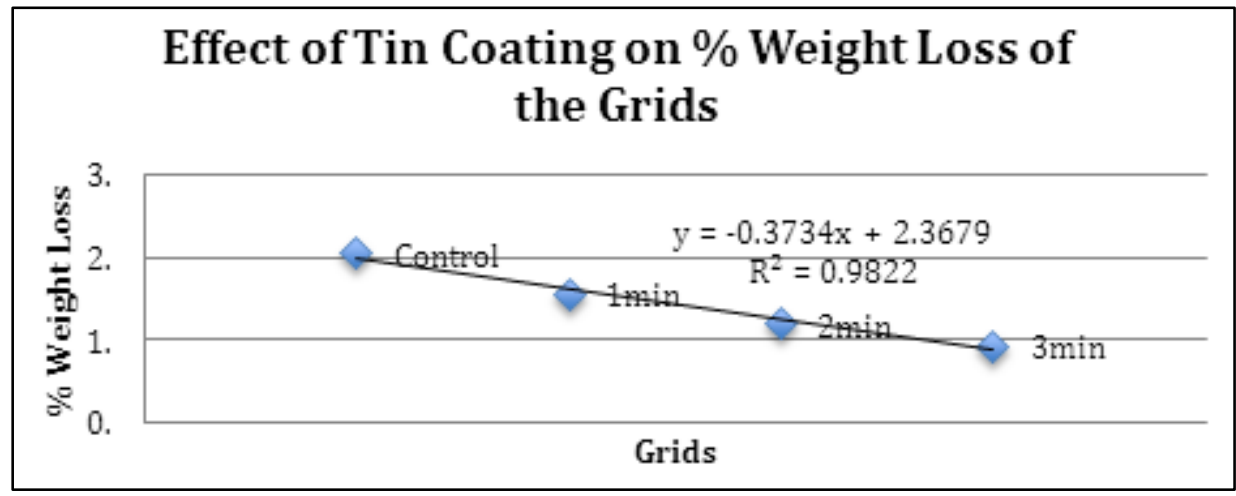

Figure 8. Effect of Sn coating on \% weight loss of the grids.

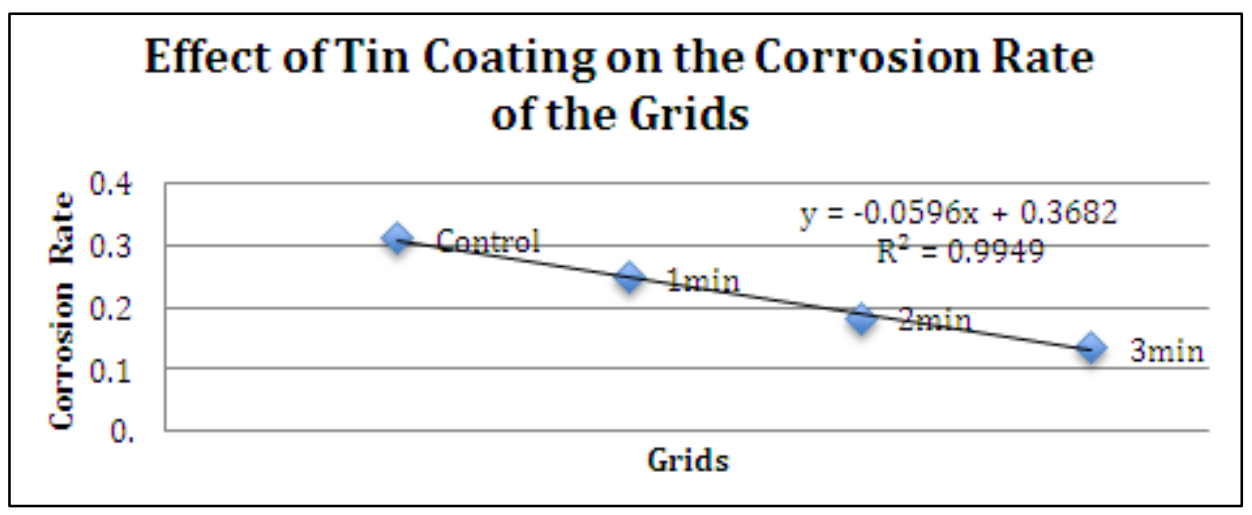

Figure 9. Effect of Sn coating on the corrosion rate of the grids. 


\section{Conclusions}

The effect of Sn coating on the corrosion behavior of the $\mathrm{Pb}-\mathrm{Ca}-\mathrm{Sn}$ grids was determined using the weight loss method. EDX analysis confirms that the amount of $\mathrm{Sn}$ is directly proportional to deposition time. The study shows that increasing the amount of Sn coating significantly reduces the weight loss and corrosion rate of the material, which then improves corrosion resistance. This is further supported by the SEM images, which show that more oxide scales were produced in the control grids as compared to the coated grids.

\section{Appendix}

One-Way ANOVA: EFFECT OF TIN COATING ON \% WEIGHT LOSS OF THE SAMPLES

\begin{tabular}{|c|c|c|c|c|c|c|}
\hline Summary & & & & & & \\
\hline Groups & Sample size & Sum & Mean & Variance & & \\
\hline Control & 5 & 10.2576 & 2.05152 & 1.32121 & & \\
\hline $1 \mathrm{~min}$ & 5 & 7.8125 & 1.5625 & 0.54985 & & \\
\hline $2 \mathrm{~min}$ & 5 & 5.9695 & 1.1939 & 0.34353 & & \\
\hline $3 \min$ & 5 & 4.6488 & 0.92976 & 0.35138 & & \\
\hline \multicolumn{7}{|l|}{ ANOVA } \\
\hline Source of Variation & $S S$ & $d f$ & $M S$ & $F$ & p-level & $F$ crit \\
\hline Between Groups & 3.54874 & 3 & 1.18291 & 1.844 & 0.17986 & 3.23887 \\
\hline Within Groups & 10.26392 & 16 & 0.64149 & & & \\
\hline Total & 13.81266 & 19 & & & & \\
\hline
\end{tabular}

One-Way ANOVA: EFFECT OF TIN COATING ON THE CORROSION RATE OF SAMPLES

\begin{tabular}{|c|c|c|c|c|c|c|}
\hline Summary & & & & & & \\
\hline Groups & Sample size & Sum & Mean & Variance & & \\
\hline Control & 5 & 1.5615 & 0.3123 & 0.00255 & & \\
\hline $\operatorname{lmin}$ & 5 & 1.2341 & 0.24682 & 0.00479 & & \\
\hline $2 \min$ & 5 & 0.9133 & 0.18266 & 0.0027 & & \\
\hline $3 \min$ & 5 & 0.6749 & 0.13498 & 0.00147 & & \\
\hline \multicolumn{7}{|l|}{ ANOVA } \\
\hline Source of Variation & $S S$ & $d f$ & $M S$ & $F$ & p-level & F crit \\
\hline Between Groups & 0.08929 & 3 & 0.02976 & 10.34754 & 0.0005 & 3.23887 \\
\hline Within Groups & 0.04602 & 16 & 0.00288 & & & \\
\hline Total & 0.13532 & 19 & & & & \\
\hline
\end{tabular}




\section{REFERENCES}

[1] Pavlov, D., Fundamentals of Lead-Acid Batteries, Lead-Acid Batteries: Science and Technology, Book, United Kingdom, 2011.

[2] Javaherdashti, R., Microbiologically Influenced Corrosion: An Engineering Insight, London, 2008.

[3] Revie, W.R. and Uhlig, H.H., Corrosion and Corrosion Control: An Introduction to Corrosion Science and Engineering, Hoboken, 2008.

[4] Callister, W.D., Rethwisch D. 2011. Materials Science and Engineering. $8^{\text {th }}$ ed. Hoboken, NJ: Wiley.

[5] Takehara, Z-I., Kanamura, K., and Makoto, K. 1990. The oxidation reaction of lead sulfate formed at the interface between the lead plate and the porous active material of a lead acid battery, Journal of the Electrochemical Society 137.

[6] Li, D-G., Zhou, G-S. Zhang, J., and Sheng, Z-M. 2007. Effect of Sn content on the properties of passive film on $\mathrm{PbSn}$ alloy in sulfuric acid solution, Science in China Series

\section{B: Chemistry 50.}

[7] Bui, N., Mattesco, P., Simon, P., Steinmetz, J., and Rocca, M. 1997. The tin effect in lead-calcium alloys, Journal of Power Sources 67.

[8] Liu, H-T, Yiang, J., Liang, H-H and Zhou, W-F. 1999. The effects of various sulphate additives on the performance of the positive electrode in lead-acid battery, Journal of Fudan University (Natural Sciences) 38.

[9] Concepcion, C. Personal communication, Philippine Batteries Incorporated, 2014.

[10] Paunovic, M., Schelsinger, M. and Synder, D., Fundamental Considerations, Modern Electroplating, Hoboken, 2010.

[11] Maltanava, H.M., Vorobyova, T.N., and Vrublevskaya, O.N. 2014. Electrodeposition of tin coatings from ethylene glycol and propylene glycol electrolytes, Surface \& Coatings Technology 254

[12] Gu, C.D., Mai, Y.J., Zhou, J.P., You, Y.H. and Tu, J.P. 2012. Non-aqueous electrodeposition of porous tin-based film as an anode for lithium-ion battery, Journal of Power Sources 214.

[13] Le B., Morrison S., Vaccaro F. Tin-Silver-Calcium Alloys for Low Corroding VRLA Positive Plates. 2002. Telecommunications Energy Conference 